\title{
LETTER
}

\section{Pushing the boundaries of diode-pumped solid-state lasers for high-energy applications}

\author{
Saumyabrata Banerjee ${ }^{1}$, Paul Mason ${ }^{1}$, Jonathan Phillips ${ }^{1}$, Jodie Smith ${ }^{1}$, Thomas Butcher ${ }^{1}$, Jacob Spear ${ }^{1}$, \\ Mariastefania De Vido ${ }^{1}$, Gary Quinn ${ }^{2}$, Danielle Clarke ${ }^{1}$, Klaus Ertel ${ }^{1}$, Cristina Hernandez-Gomez ${ }^{1}$, \\ Chris Edwards ${ }^{1}$, and John Collier ${ }^{1}$ \\ ${ }^{1}$ Central Laser Facility, STFC Rutherford Appleton Laboratory, Didcot OX11 OQX, UK \\ ${ }^{2}$ Heriot-Watt University, School of Engineering and Physical Sciences, EH14 4AS, UK \\ (Received 12 February 2020; revised 14 March 2020; accepted 2 April 2020)
}

\begin{abstract}
We report on the successful demonstration of a $150 \mathrm{~J}$ nanosecond pulsed cryogenic gas cooled, diode-pumped multi-slab Yb:YAG laser operating at $1 \mathrm{~Hz}$. To the best of our knowledge, this is the highest energy ever recorded for a diodepumped laser system.
\end{abstract}

Keywords: cryogenic gas cooling; diode-pumped solid-state laser; multi-slab amplifier; Yb:YAG

\section{Introduction}

The next generation of laser facilities will offer high-energy pulses as well as high repetition rates, enabling 'real-world', high-throughput applications and a wide range of science that requires the acquisition of high volumes of data. Such applications include advanced materials processing and laser shock peening ${ }^{[1]}$, high energy density (HED) physics studies $^{[2]}$ and pumping of ultra-high-intensity fs petawattclass lasers to generate secondary radiation (X-rays and $\gamma$ rays) and particle (electrons, protons and muon) sources ${ }^{[3,4]}$.

The Center for Advanced Laser Technology and Applications (CALTA) at STFC's Central Laser Facility (CLF) is a pioneer of 'DiPOLE' multi-slab, cryogenic gas cooled Yb:YAG amplifier technology. In 2015, a single-stage prototype cryogenic gas cooled amplifier, called the DiPOLE system, achieved an output in excess of $10 \mathrm{~J}$ at $10 \mathrm{~Hz}$, with an optical-to-optical efficiency of $22 \%[5]$. Further, energy scaling up to $100 \mathrm{~J}$ at $10 \mathrm{~Hz}$ was reported for the first time in a two-stage cryo-amplifier ${ }^{[6]}$, delivered to the HiLASE facility ${ }^{[7]}$ at Dolni Brezany in the Czech Republic.

In this paper, we report the scaling up of DiPOLE technology to a pulse energy of $150 \mathrm{~J}$ at $1 \mathrm{~Hz}$. To the best of our knowledge, this is the highest energy achieved by a diode-pumped solid-state laser. These results were obtained

Correspondence to: S. Banerjee, Central Laser Facility, STFC Rutherford Appleton Laboratory, Didcot OX11 0QX, UK.

Email: saumyabrata.banerjee@stfc.ac.uk during the development of a two-stage cryogenic gas cooled amplifier, called D100X, to be supplied to the European XFEL facility ${ }^{[8]}$ for use in HED science experiments. The nominal operating condition for the laser is $100 \mathrm{~J}, 10 \mathrm{~ns}$ at $10 \mathrm{~Hz}$ with advanced temporal pulse shaping capabilities to enable low entropy compression of materials.

\section{Setup and results}

Figure 1 shows the three-dimensional (3D) model of the D100X laser system divided into three main components, namely, front end (FE), first-stage cryo-amplifier (MA1) and second-stage cryo-amplifier (MA2). Design details of each amplifier stage have been reported previously ${ }^{[9]}$. As the amplifiers (MA1 and MA2) require cooling down to cryogenic temperatures, the system requires about $2.5 \mathrm{~h}$ of cool-down time from room temperature before the setup is ready for high-energy amplification. In the $10 \mathrm{~Hz}$ operating mode, a pulse energy of $105 \mathrm{~J}$ (1.05 $\mathrm{kW}$ average power) was obtained when MA2 was seeded by $6 \mathrm{~J}, 10 \mathrm{~ns}$ pulses from MA1. The helium gas flow, temperature and diode pump pulse duration for MA2 were maintained at $180 \mathrm{~g} / \mathrm{s}, 140 \mathrm{~K}$ and $650 \mu \mathrm{s}$, respectively. The inset in Figure 1 shows the far-field profile at $\mathrm{kW}$-level operation. For a $3 \mathrm{~m}$ focal length lens, the focal spot size was $87.9 \mu \mathrm{m}$ ( $x$-axis) by $105.4 \mu \mathrm{m}$ ( $y$-axis). This is 1.6 and 2.0 times the diffraction limit for a square super-Gaussian (SG) beam, and this corresponds to 


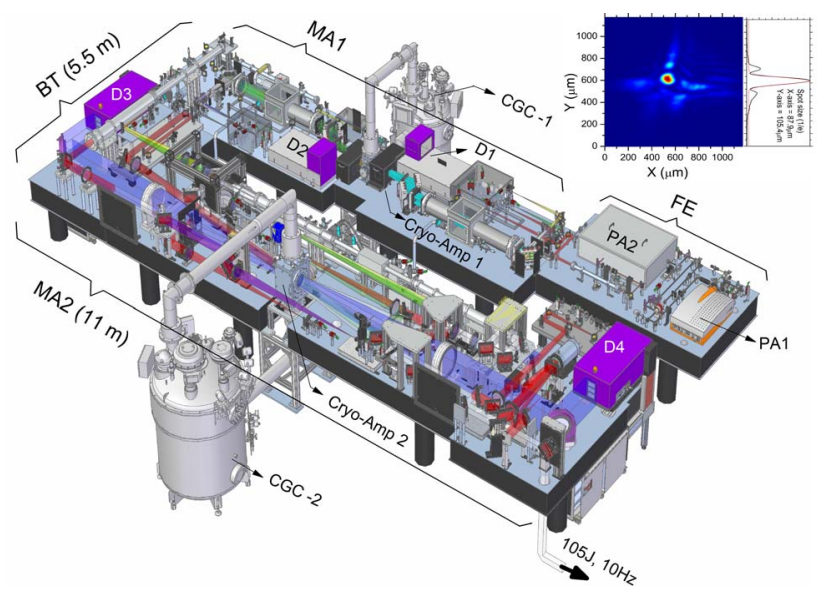

Figure 1. $3 \mathrm{D}$ model of $\mathrm{D} 100 \mathrm{X}$ laser showing $\mathrm{FE}=$ front end; $\mathrm{BT}$ $=$ beam transport; $\mathrm{PA}=$ room-temperature pre-amplifier $(1=\mathrm{Yb}: \mathrm{CaF} 2$ regenerative, $2=$ Yb:YAG multi-pass); $\mathrm{MA}=$ main cryogenic amplifier $(1$ $=$ stage $1,2=$ stage 2$) ; C G C=$ cryogenic gas coolers; $\mathrm{D}=940 \mathrm{~nm}$ diode pumps ( $1 \& 2$ for MA-1, $3 \& 4$ for MA-2). The inset shows the far-field image recorded at $105 \mathrm{~J}, 10 \mathrm{~Hz}$ operation.

$50 \%$ energy encircled in a $32 \mu \mathrm{m}$ radius.

As precise control over the temporal profile is important for achieving efficient densification of materials in HED experiments, an automated pulse shaping capability was incorporated into the D100X laser system. A typical example is shown in Figure 2(a), where the desired temporal profile was a $10 \mathrm{~ns}$ flat-top output. An initial temporal profile was created using an arbitrary waveform generator (AWG), and fed through an amplifier chain, which modified the temporal shape depending on the amplification at different stages. The output temporal shape was then fed to the control software, which calculates a new profile based on the difference between the desired and present temporal shapes. The new profile was fed back to the AWG, and the process was repeated till the desired temporal profile was obtained.
Figure 2(a) shows an example of automatic pulse shaping at $>75 \mathrm{~J}, 10 \mathrm{~Hz}$ operation, where four iterations of the shaping cycles were required to achieve a flat-top temporal profile. Figure 2(b) shows the long-term energy stability of the laser for $6 \mathrm{~h}$ operation $\left(2 \times 10^{5}\right.$ shots $)$ with an RMS value of $0.8 \%$.

To explore the energy scalability of the system, the seed input and pulse duration from MA1 were increased to $10 \mathrm{~J}$ and $15 \mathrm{~ns}$, respectively, at $1 \mathrm{~Hz}$. The MA2 temperature was decreased to $125 \mathrm{~K}$ and the diode pump pulse duration was increased to $1 \mathrm{~ms}$. Output energetics for the experiments are shown in Figure 3(a) with a conversion efficiency of $26 \%$ measured for $150 \mathrm{~J}$ output. It should be noted that a peak efficiency of $\sim 34 \%$ was measured for an output energy near $100 \mathrm{~J}$. Figure 3(b) shows the long-term operation of the system at $150 \mathrm{~J}, 1 \mathrm{~Hz}$; the near-field (NF) profile at $150 \mathrm{~J}$, $1 \mathrm{~Hz}$ is also shown. An increase in the repetition rate to $10 \mathrm{~Hz}$ at $150 \mathrm{~J}$ will require damage-resilient optics (for the increase in fluence) and higher gas flow (for the increase in heat load). The circular and vertical features seen in the NF profile are caused by the interference effect within the neutral density filters used in the diagnostic channel. These fringes are not visible for a profile taken on a light sensitive paper. An SG profile of order 10 fits the $y$-axis cross-section of the NF. Figure 3(c) shows the temporal profiles of the FE, mainamplifier 1 (MA1) and main-amplifier 2 (MA2) during the $150 \mathrm{~J}, 1 \mathrm{~Hz}$ operation.

The dependence of laser performance on the MA2 temperature, diode pump input energy and MA1 seed energy was studied further with the results tabulated in Table 1. Note that efficiency improves with a reduction of amplifier temperature. A similar trend is observed for an increase in seed energy (MA1) for a fixed temperature (MA2). Although the extracted energy increases to $150 \mathrm{~J}$ at $600 \mathrm{~J}$ pump input ( $1 \mathrm{~ms}$ duration), the efficiency reduces and remains constant even with an increase of the seed input. This result indicates that an optimum combination of temperature, seed and pump
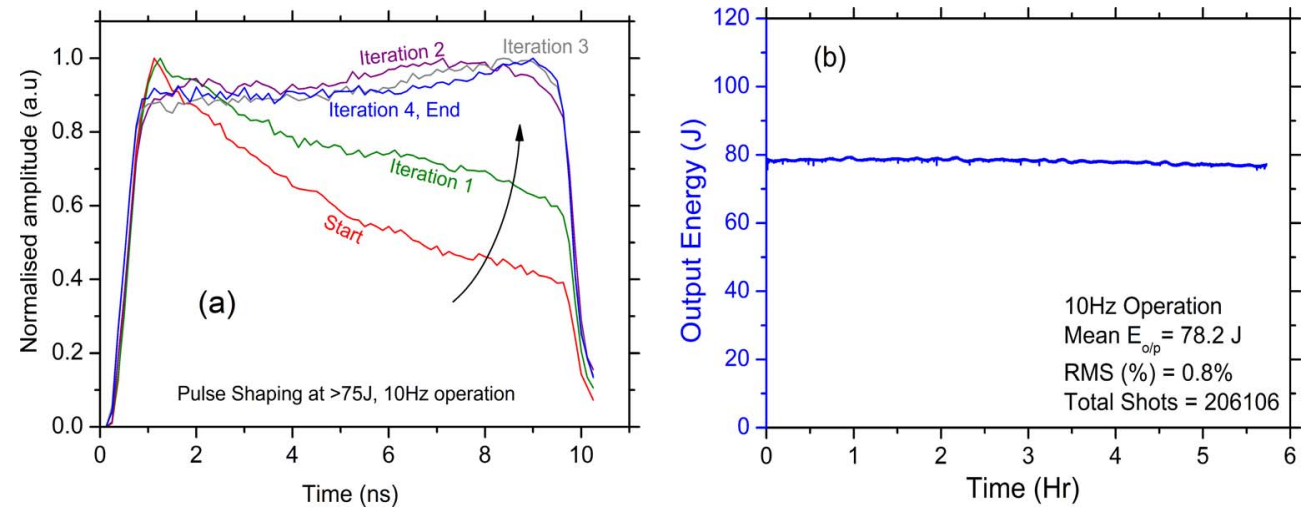

Figure 2. (a) Example of automatic pulse shaping capability of the D100X laser for achieving a flat-top temporal profile at $>75 \mathrm{~J}, 10 \mathrm{~Hz}$ operation; (b) long-term stability over $6 \mathrm{~h}$ at $10 \mathrm{~Hz}$. 

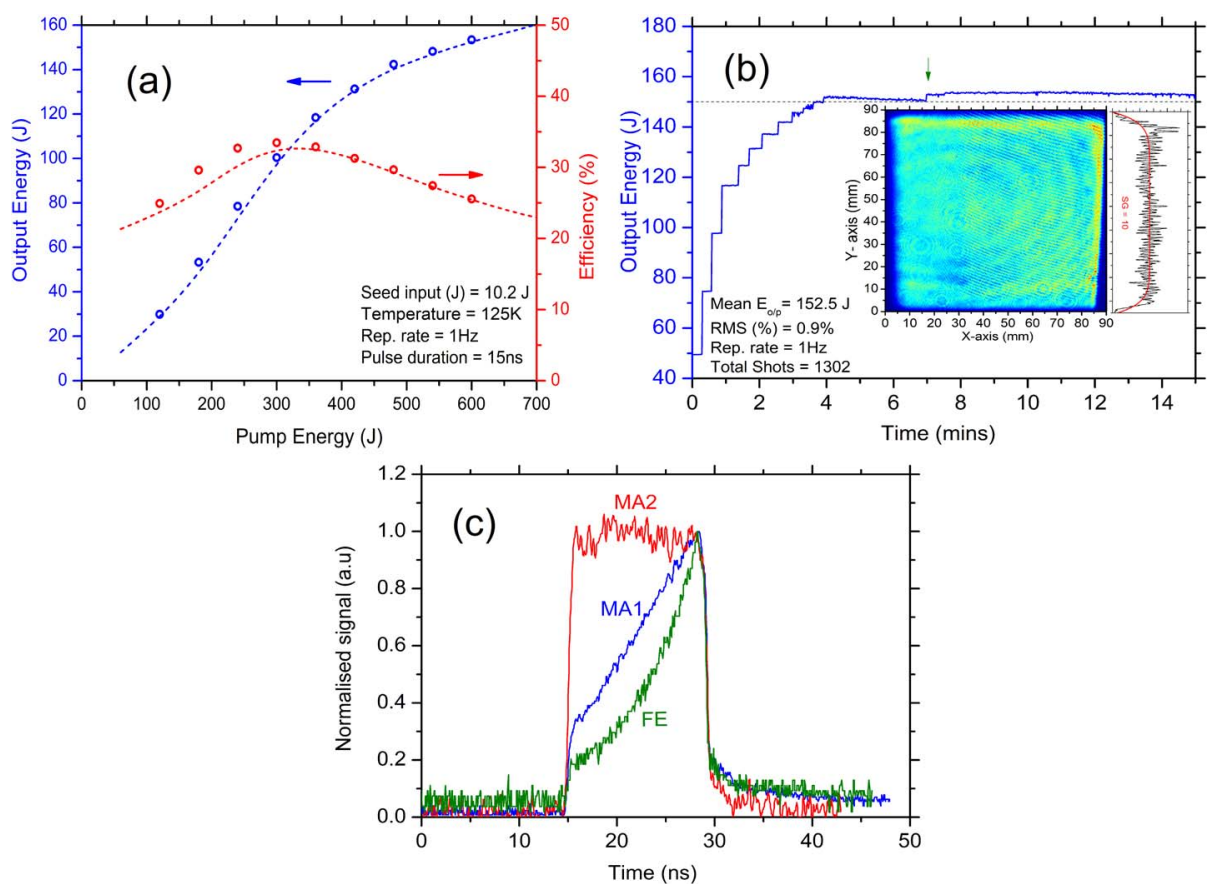

Figure 3. (a) Output energetics, experimentally measured (circle) and numerically calculated (dotted lines); (b) long-term operation at $150 \mathrm{~J}, 1 \mathrm{~Hz}$, and the inset shows the near-field profile at $150 \mathrm{~J}, 1 \mathrm{~Hz}$ operation; (c) temporal profile of the front end (FE), main-amplifier 1 (MA1) and main-amplifier 2 (MA2) during $150 \mathrm{~J}, 1 \mathrm{~Hz}$ operation.

Table 1. D100X laser system performance at different temperatures, seed and pump inputs.

\begin{tabular}{lcccc}
\hline Temp. (K) & Seed $(\mathrm{J})$ & Pump $(\mathrm{J})$ & Energy output $(\mathrm{J})$ & Efficiency $(\%)$ \\
\hline $\mathbf{1 4 0}$ & 5.6 & 390 & 103.4 & 26.5 \\
$\mathbf{1 3 5}$ & 5.6 & 390 & 109.7 & 28.1 \\
$\mathbf{1 3 0}$ & 5.6 & 390 & 112.8 & 28.9 \\
$\mathbf{1 2 5}$ & $\mathbf{5 . 6}$ & 390 & 116.0 & 29.7 \\
125 & $\mathbf{6 . 9}$ & 390 & 120.7 & 30.9 \\
125 & $\mathbf{8 . 2}$ & 390 & 124.8 & 32.0 \\
130 & 9.1 & $\mathbf{6 0 0}$ & 150.9 & 25.1 \\
125 & 9.1 & $\mathbf{6 0 0}$ & 152.4 & 25.4 \\
125 & 10.2 & $\mathbf{6 0 0}$ & 153.7 & 25.6 \\
\hline
\end{tabular}

input is required to extract the maximum energy with best efficiency.

\section{Conclusion}

In summary, we have demonstrated $150 \mathrm{~J}, 1 \mathrm{~Hz}$ nanosecond pulsed output from a cryogenic gas cooled, multi-slab Yb:YAG laser. The system has now exceeded its design specification and is currently being installed in the laser laboratory at XFEL by a joint team of XFEL and CLF engineers and scientists.

\section{References}

1. P. Peyre and R. Fabbro, Opt. Quant. Electron. 27, 1213 (1995).

2. R. P. Drake, Nucl. Fusion 59, 035001 (2019).

3. M. D. Perry, J. A. Sefcik, T. Cowan, S. Hatchett, A. Hunt, M. Moran, D. Pennington, R. Snavely, and S. C. Wilks, Rev. Sci. Inst. 70, 265 (1999).

4. T. Tajima and J. M. Dawson, Phys. Rev. Lett. 43, 267 (1979).

5. S. Banerjee, K. Ertel, P. D. Mason, P. J. Phillips, M. De Vido, J. M. Smith, T. J. Butcher, C. Hernandez-Gomez, R. J. S. Greenhalgh, and J. L. Collier, Opt. Express 23, 19542 (2015).

6. P. Mason, M. Divoký, K. Ertel, J. Pilař, T. Butcher, M. Hanuš, S. Banerjee, J. Phillips, J. Smith, M. De Vido, A. Lucianetti, C. Hernandez-Gomez, C. Edwards, T. Mocek, and J. Collier, Optica 4, 438 (2017).

7. O. Novák, T. Miura, M. Smrž, M. Chyla, S. S. Nagisetty, J. Mužík, J. Linnemann, H. Turčičová, V. Jambunathan, O. Slezák, M. SawickaChyla, J. Pilař, S. Bonora, M. Divoký, J. Měsíček, A. Pranovich, P. Sikocinski, J. Huynh, P. Severová, P. Navrátil, D. Vojna, L. Horáčková, K. Mann, A. Lucianetti, A. Endo, D. Rostohar, and T. Mocek, Appl. Sci. 5, 637 (2015).

8. P. Vagovič, T. Sato, L. Mikeš, G. Mills, R. Graceffa, F. Mattsson, P. Villanueva-Perez, A. Ershov, T. Faragó, J. Uličný, H. Kirkwood, R. Letrun, R. Mokso, M. Zdora, M. Olbinado, A. Rack, T. Baumbach, J. Schulz, A. Meents, H. Chapman, and A. Mancuso, Optica 6, 1106 (2019).

9. P. D. Mason, S. Banerjee, K. Ertel, P. J. Phillips, T. J. Butcher, J. M. Smith, M. De Vido, S. Tomlinson, O. Chekhlov, W. Shaikh, S. Blake, P. Holligan, M. Divoky, J. Pilar, C. HernandezGomez, R. J. S. Greenhalgh, and J. L. Collier, Proc. SPIE 9513, 951302 (2015). 